Check for updates

Cite this: RSC Adv., 2019, 9, 23642

Received 27th June 2019 DOI: $10.1039 / c 9 r a 04865 k$ rsc.li/rsc-advances Accepted 23rd July 2019

\section{Quantification and isotherm modelling of competitive phosphate and silicate adsorption onto micro-sized granular ferric hydroxide $\uparrow$}

\author{
Inga Hilbrandt, iD *a Vito Lehmann, ${ }^{a}$ Frederik Zietzschmann, ${ }^{b}$ Aki Sebastian Ruhl ${ }^{\mathrm{C}}$ \\ and Martin Jekel ${ }^{a}$
}

\begin{abstract}
Adsorption onto ferric hydroxide is a known method to reach very low residual phosphate concentrations. Silicate is omnipresent in surface and industrial waters and reduces the adsorption capacity of ferric hydroxides. The present article focusses on the influences of silicate concentration and contact time on the adsorption of phosphate to a micro-sized iron hydroxide adsorbent $(\mu \mathrm{GFH})$ and fits adsorption data to multi-component adsorption isotherms. In Berlin drinking water (DOC of approx. $4 \mathrm{mg} \mathrm{L}^{-1}$ ) at $\mathrm{pH} 7.0$, loadings of $24 \mathrm{mg} \mathrm{g}^{-1} \mathrm{P}$ (with $3 \mathrm{mg} \mathrm{L}^{-1}$ initial $\mathrm{PO}_{4}{ }^{3-}-\mathrm{P}$ ) and $17 \mathrm{mg} \mathrm{L}^{-1} \mathrm{Si}$ (with $9 \mathrm{mg} \mathrm{L}^{-1}$ initial Si) were reached. In deionized water, phosphate shows a high percentage of reversible bonds to $\mu \mathrm{GFH}$ while silicate adsorption is not reversible probably due to polymerization. Depending on the initial silicate concentration, phosphate loadings are reduced by 27,33 and $47 \%$ (for equilibrium concentrations of $1.5 \mathrm{mg} \mathrm{L}^{-1}$ ) for 9,14 and $22 \mathrm{mg} \mathrm{L}^{-1}$ Si respectively. Out of eight tested multi-component adsorption models, the Extended Freundlich Model Isotherm (EFMI) describes the simultaneous adsorption of phosphate and silicate best. Thus, providing the means to predict and control phosphate removal. Longer contact times of the adsorbent with silicate prior to addition of phosphate reduce phosphate adsorption significantly. Compared to 7 days of contact with silicate $\left(c_{0}=10 \mathrm{mg} \mathrm{L}^{-1}\right)$ prior to phosphate $\left(c_{0}=3 \mathrm{mg} \mathrm{L}^{-1}\right.$ ) addition, 28 and 56 days reduce the $\mu \mathrm{GFH}$ capacity for phosphate by 21 and $43 \%$, respectively.
\end{abstract}

\section{Introduction}

Phosphate loads in up to $20 \%$ of European surface waters have to be drastically reduced to reach the good ecological status as demanded by the European water framework directive. ${ }^{1}$ Critical phosphate concentrations for slowly flowing or dammed waters are set as $0.1 \mathrm{mg} \mathrm{L}^{-1}$ total phosphorus (TP). ${ }^{2}$ In Germany, the majority of surface waters exceed this value, especially shallow and polymictic lakes. Depending on the lake type, even lower values of $0.02-0.06 \mathrm{mg} \mathrm{L}^{-1}$ have been suggested in order to limit algae growth and to reach a good status. ${ }^{3}$

Conventional techniques for $\mathrm{P}$ removal include precipitation with di- or trivalent metal ions and biological removal. Low residual phosphate concentrations are achieved with high doses of flocculants. Besides high costs, the advanced treatment leads to an increased input of salts, increased sludge volumes and the need for large sedimentation tanks. A more simple and

${ }^{a}$ Technische Universität Berlin, Chair of Water Quality Control, Str. des 17. Juni 135, 10623 Berlin, Germany. E-mail: Inga.Hilbrandt@tu-berlin.de

${ }^{b}$ TU Delft, Water Management, Stevinweg 1, 2628 CN Delft, Netherlands

${ }^{c}$ Umweltbundesamt, Schichauweg 58, 12307 Berlin, Germany

$\dagger$ Electronic supplementary information (ESI) available. See DOI: 10.1039/c9ra04865k space saving alternative is the use of adsorption as it is a suitable method to reach low $\mathrm{P}$ concentrations. ${ }^{4}$ Many studies on the adsorption of phosphate onto iron oxides have been conducted..$^{5-8}$ Adsorption of phosphate as a polyprotic anion takes place over a wide $\mathrm{pH}$ range and has its maximum at values below the $\mathrm{pH}_{\mathrm{PZC}}$ of the adsorbent.

Adsorbents are not specific for one target substance but accumulate a mixture of competing water constituents. Competitive adsorption of phosphate onto iron hydroxides was widely studied.,8-11 While sulfate and chloride were shown to have no effects ${ }^{12}$ and bivalent cations $\left(\right.$ e.g. $\left.\mathrm{Ca}^{2+}, \mathrm{Mg}^{2+}\right)$ can have beneficial surface complexation effects on phosphate, bicarbonate and silicate proved to have adverse impacts. ${ }^{13}$

Silicate is released during wreathing of Si-containing minerals and occurs in natural waters in concentrations of 3 to $30 \mathrm{mg} \mathrm{L}{ }^{-1}$, mainly as $\mathrm{Si}(\mathrm{OH})_{4} \cdot{ }^{14}$ The sorption of silicate onto iron hydroxides receives ongoing attention..$^{\mathbf{9 1 3 - 1 9}}$ The adsorption is $\mathrm{pH}$-dependent with increasing adsorption until the silicate species changes from $\mathrm{H}_{4} \mathrm{SiO}_{4}^{0}$ to $\mathrm{H}_{3} \mathrm{SiO}_{4}{ }^{-}$at $\mathrm{p} K_{\mathrm{a}} 9.82 .{ }^{13}$ The adsorption is accompanied by a net release of protons, which results in a decrease of the iso-electrical point of the adsorbent surface. At the $\mathrm{pH}_{\mathrm{PZC}}$ of the adsorbent the building of two different surface complexes is proposed by Hiemstra. ${ }^{13} \mathrm{~A}$ binuclear bidentate complex with exchange of two ligands 
resulting in $\equiv(\mathrm{FeO})_{2} \mathrm{Si}(\mathrm{OH})_{2}$ and a mononuclear monodentate complex $\equiv(\mathrm{FeOHFeO}) \mathrm{Si}(\mathrm{OH})_{3}$. At low concentrations and low $\mathrm{pH}$ values silicate is mostly present as monomers, whereas the amount of oligomeric and polymeric silicates increases steeply at circum-neutral $\mathrm{pH}$ values. ${ }^{13}$ Polymerization was observed at molar ratios of $\mathrm{Si} / \mathrm{Fe}$ below $0.1 .^{\mathbf{1 4 , 1 5 , 2 0}}$

In competitive adsorption experiments phosphate was less affected by silicate than oppositely. ${ }^{13}$ While at low $\mathrm{pH}$-values the effect of phosphate on silicate was very large, it was less for higher $\mathrm{pH}$-values. For the competitive adsorption of silicate and arsenate no influence was found for $\mathrm{pH}$ values below 9, but silicate was able to replace arsenate when adsorbing onto ferrihydrite above $\mathrm{pH} 9 .^{20}$ However, polymerization of silicate was prevented when arsenate was added first. ${ }^{\mathbf{1 4}}$ They conclude that polymerization is a surface controlled process. Christl et al. ${ }^{\mathbf{1 8}}$ suggest that a long pre-equilibration of the adsorbent with silicate might alter the surface configuration of the adsorbent, favouring the formation of oligomers and polymers and thus reducing reactivity. No binary adsorption isotherms to fit this data have been developed yet to our knowledge.

Given the high relevance of phosphate for surface water quality, the adverse impacts of the ubiquitously present adsorptive competitor silicate requires further elucidation. The current study highlights the effects of variable silicate concentrations, preloading times, and iron-complexation on phosphate adsorption onto a micro-sized iron hydroxide $(\mu \mathrm{GFH}$, characterized in a previous study ${ }^{\mathbf{2 1}}$ ). In addition, various bisolute models are tested for describing the observed competitive adsorption. Further, we also tested the potential reversibility of silicate and phosphate adsorption under practically relevant conditions. The provided results improve the understanding of competitive phosphate-silicate adsorption on iron hydroxide surfaces, thus providing better means for process control and safety.

\section{Material and methods}

\subsection{Adsorbent}

Micro-sized ferric hydroxide was obtained from GEH Wasserchemie (Osnabrück, Germany). Granular ferric hydroxide (GFH) is produced by precipitation of $\mathrm{Fe}(\mathrm{OH})_{3}$ from a $\mathrm{FeCl}_{3}$ solution and subsequent conditioning of the resulting sludge to obtain stable granules of up to $3 \mathrm{~mm}$ grain size. ${ }^{22}$ In the current study, we used only particles $<0.3 \mathrm{~mm}$, potentially increasing adsorption kinetics and overall loadings. ${ }^{23}$ Conventional GFH consists to $50-70 \%$ of akaganeite $(\beta-\mathrm{FeOOH})$, ferrihydrite, and other iron oxides. ${ }^{24}$ Saha et al. ${ }^{25}$ reported a point of zero charge $\left(\mathrm{pH}_{\mathrm{PzC}}\right)$ of 7.5 for GFH. The supplied $\mu \mathrm{GFH}$ material had a water content of approx. $53 \%$ and a specific surface area of approx. $300 \mathrm{~m}^{2} \mathrm{~g}^{-1}$ dry weight. Sieve analyses showed a contribution of 30, 25, and $45 \%$ weight of the fractions $<63 \mu \mathrm{m}, 63-120 \mu \mathrm{m}$ and $120-300$ $\mu \mathrm{m}$, respectively, and particle counting with a particle analyser (PAMAS SVSS) revealed that 99\% of the particles were smaller than $63 \mu \mathrm{m} .^{21}$ The $\mu \mathrm{GFH}$ was wet-sieved to the desired grain fractions and then air-dried at room temperature. The residual water content varied between 10 and $20 \%$. Previous experiments showed no alteration of the material due to drying. A detailed characterization of the adsorbent was provided by Hilbrandt et $a .^{21}$

\subsection{Experimental set-up}

Batch experiments were conducted at room temperature $(20 \pm 2$ $\left.{ }^{\circ} \mathrm{C}\right)$ to obtain adsorption isotherms. All chemicals and reagents used were of analytical grade or higher. $\mathrm{NaCl}$ was added to deionized water (DI) to set an ionic strength of $10 \mathrm{mmol} \mathrm{L}^{-1}$. Initial phosphate and silicate concentrations (added as $\mathrm{KH}_{2} \mathrm{PO}_{4}$ and $\mathrm{Na}_{2} \mathrm{SiO}_{3} \cdot 5 \mathrm{H}_{2} \mathrm{O}$ ) were adjusted to $4 \mathrm{mg} \mathrm{L}{ }^{-1} \mathrm{P}$ and $10 \mathrm{mg} \mathrm{L}^{-1}$ Si respectively (unless indicated otherwise). $2 \mathrm{mmol} \mathrm{L}^{-1} \mathrm{MES}$ (2$\left(N\right.$-morpholino)ethanesulfonic acid, $\left.\mathrm{p} K_{\mathrm{a}}=6.1\right)$, BES $(N, N$-bis $(2-$ hydroxyethyl)-2-aminoethanesulfonic acid, $\mathrm{p} K_{\mathrm{a}}=7.1$ ) or TAPS ( $N$-tris(hydroxymethyl)methyl-3-aminopropanesulfonic acid, $\left.\mathrm{p} K_{\mathrm{a}}=8.4\right)$ were used to buffer the $\mathrm{pH}$ value, adjusted with $\mathrm{NaOH}$. All buffer substances were purchased from Sigma Aldrich (Germany). No significant adsorption of the buffer substances onto $\mu \mathrm{GFH}$ was found in preliminary tests and thus no competition with the target substances was expected. The isotherms were obtained by varying the adsorbent doses between 40 and $500 \mathrm{mg} \mathrm{L}^{-1}$. Dry $\mu \mathrm{GFH}$ was added to $100 \mathrm{~mL}$ or $150 \mathrm{~mL}$ batches of test solutions containing the target substances and shaken at room temperature at $220 \mathrm{rpm}$. After $72 \mathrm{~h}$, the adsorbent was separated using membrane filtration ( $0.45 \mu \mathrm{m}$, cellulose nitrate), as kinetic experiments showed no further adsorption after that time period. ${ }^{26}$

For desorption experiments the suspensions were centrifuged after $72 \mathrm{~h}$ contact time (as described above, without adsorbent removal by filtration), following a method introduced by Aschermann et al. ${ }^{27} 95 \mathrm{~mL}$ of the solution were removed after centrifugation and the same volume of desorption solution was added. The desorption solution corresponded to the adsorption solution without the target substances. The desorption batches were shaken for another $72 \mathrm{~h}$ prior to adsorbent removal by filtration and subsequent analyses.

For the influence of silicate in simultaneous adsorption, $\mu \mathrm{GFH}$ was added to the above described test solution containing $3 \mathrm{mg} \mathrm{L}^{-1} \mathrm{PO}_{4}-\mathrm{P}$ and varying concentrations of silicate $(6,10$ and $\left.18 \mathrm{mg} \mathrm{L}^{-1}\right)$. In addition to competitive phosphate-silicate tests in DI-water, drinking water tests were conducted. The concentrations of $6,10,18 \mathrm{mg} \mathrm{L}^{-1} \mathrm{Si}$ were added to drinking water which itself had a Si concentration of $6 \mathrm{mg} \mathrm{L}^{-1}$, resulting in final $\mathrm{Si}$ concentrations of $12,16,24 \mathrm{mg} \mathrm{L}^{-1}$. Sequential adsorption experiments were carried out as described for the single solute tests but with the addition of the second substance from a highly concentrated stock solution after a contact time of $72 \mathrm{~h}$. The equilibrium concentrations of both substances were measured after the cumulative adsorption time of $144 \mathrm{~h}$. Further experiments were carried out with 7, 28 and 56 d contact time between silicate and $\mu \mathrm{GFH}$ with subsequent addition of phosphate and additional $7 \mathrm{~d}$ of contact time in the binary solution.

\subsection{Analytical methods}

$\mu \mathrm{GFH}$ doses in the batch experiments were gravimetrically controlled by membrane filtration through pre-washed $0.45 \mu \mathrm{m}$ 
cellulose nitrate filters, which were dried for $24 \mathrm{~h}$ at $105^{\circ} \mathrm{C}$ and weighed before and after filtration. Orthophosphate was quantified via flow injection analysis according to ISO. ${ }^{28}$ Silicate concentrations were determined photometrically (Lambda 12, PerkinElmer) with test kits (Spectroquant, Merck) using $10 \mathrm{~mm}$ glass cuvettes. The uncertainty of the measurement is shown with a 95\% confidence interval expressing the summed up errors of the experimental and analytical processes.

\subsection{Adsorption modelling}

2.4.1. Single component isotherms. The adsorption equilibrium in a single component system can be described by isotherm equations of Freundlich (eqn (1)) with the equilibrium loading $q_{i}\left(\mathrm{mg} \mathrm{g}^{-1}\right)$, the Freundlich coefficient $K_{\mathrm{F}, i}\left(\mathrm{~L}^{n}(\mathrm{~g}\right.$ $\left.\left.\mathrm{mg}^{n-1}\right)^{-1}\right)$, the equilibrium concentration $c_{i}\left(\mathrm{mg} \mathrm{L}^{-1}\right)$ and the Freundlich exponent $n_{i}(-)$, of Langmuir (eqn (2)) with the maximum loading $q_{\mathrm{m}, i}\left(\mathrm{mg} \mathrm{g}^{-1}\right)$ and the Langmuir coefficient $K_{\mathrm{L}, i}\left(\mathrm{~L} \mathrm{mg}{ }^{-1}\right)$ or of Redlich-Peterson (R-P, eqn (3)) with the coefficients $A_{i}\left(\mathrm{~L} \mathrm{~g}^{-1}\right), b_{i}\left(\mathrm{~L} \mathrm{mg}^{-1}\right)^{\beta}$ and $\beta(-)$.

$$
\begin{aligned}
q_{i} & =K_{\mathrm{F}, i} c_{i}^{n_{i}} \\
q_{i} & =\frac{q_{\mathrm{m}, i} K_{\mathrm{L}, i} c_{i}}{1+K_{\mathrm{L}, i} c_{i}} \\
q_{i} & =\frac{A_{i} c_{i}}{1+b_{i} c_{i}{ }^{\beta}}
\end{aligned}
$$

2.4.2. Multi-component isotherms. For the description of adsorption in multi-solute systems, multi-component isotherm equations were developed by extending the above described single component isotherms. ${ }^{29}$ The following equations were used in this work:

(a) Non-modified Langmuir multi-component isotherm (NLMI) with the Langmuir parameters $q_{\mathrm{m}, i}$ and $K_{\mathrm{L}, i}$ derived from the single-component isotherms ${ }^{30}$

$$
q_{\mathrm{e}, j}=\frac{q_{\mathrm{m}, i} K_{\mathrm{L}, i} c_{\mathrm{e}, i}}{1+\sum_{j=1}^{N} K_{\mathrm{L}, j} c_{\mathrm{e}, j}}
$$

(b) Modified Langmuir multi-component isotherm (MLMI) with the Langmuir parameters $q_{\mathrm{m}, i}$ and $K_{\mathrm{L}, i}$ derived from the single-component isotherms and an additional interaction term $\eta_{i}{ }^{31}$ number of fitting parameters: $2\left(n_{i}, n_{j}\right)$

$$
q_{\mathrm{e}, j}=\frac{q_{\mathrm{m}, i} K_{\mathrm{L}, i}\left(c_{\mathrm{e}, i} / \eta_{i}\right)}{1+\sum_{j=1}^{N} K_{\mathrm{L}, j}\left(c_{\mathrm{e}, j} / \eta_{j}\right)}
$$

(c) Extended Langmuir multi-component isotherm (ELMI) with a total maximum loading of both components $q_{\max }(\mathrm{mg}$ $\mathrm{g}^{-1}$ ) and Langmuir coefficients $K_{i}$ and $K_{j}$ in the binary solution, ${ }^{32}$ number of fitting parameters: $3\left(q_{\max }, K_{i}, K_{j}\right)$

$$
q_{\mathrm{e}, j}=\frac{q_{\mathrm{max}} K_{i} c_{\mathrm{e}, i}}{1+\sum_{j=1}^{N} K_{j} c_{\mathrm{e}, j}}
$$

(d) Extended Freundlich multi-component isotherm (EFMI) with the Freundlich parameters $K_{\mathrm{F}}$ and $n$ from the singlecomponent isotherm and the binary coefficients $x_{i}, y_{i}$ and $z_{i},{ }^{31,33}$ number of fitting parameters: $6\left(x_{1}, y_{1}, z_{1}, x_{2}, y_{2}, z_{2}\right)$

$$
\begin{aligned}
& q_{\mathrm{e}, 1}=\frac{K_{\mathrm{F}, 1} c_{\mathrm{e}, 1}{ }^{\left(n_{1}+x_{1}\right)}}{c_{\mathrm{e}, 1}{ }^{x_{1}}+y_{1} c_{\mathrm{e}, 2}{ }^{z_{1}}} \\
& q_{\mathrm{e}, 2}=\frac{K_{\mathrm{F}, 2} c_{\mathrm{e}, 2}\left(n_{2}+x_{2}\right)}{c_{\mathrm{e}, 2}^{x_{2}}+y_{2} c_{\mathrm{e}, 1}{ }^{z_{2}}}
\end{aligned}
$$

(e) Sheindorf-Rebuhn-Sheintuch equation (SRS) with the Freundlich coefficient from the single-solute isotherm $K_{\mathrm{F}}$ and the interaction factor $a_{i j},{ }^{34}$ number of fitting parameters: $2\left(a_{i j}\right.$, $\left.a_{j i}\right)$

$$
q_{i}=K_{\mathrm{F}, i} c_{i}\left(\sum_{j=1}^{N} a_{i j} c_{j}\right)^{\left(n_{i}-1\right)}
$$

(f) Non-modified Redlich-Peterson multi-component isotherm (NRPMI) with the R-P single-component isotherm parameters $A_{i}, b_{i}$ and $\beta_{i}^{35}$

$$
q_{\mathrm{e}, j}=\frac{A_{i} c_{\mathrm{e}, i}}{1+\sum_{j=1}^{N} b_{j} c_{\mathrm{e}, j} \beta_{j}}
$$

(g) Modified Redlich-Peterson multi-component isotherm (MRPMI) with the single-component isotherm parameters and an additional interaction factor $\eta_{i},{ }^{35}$ number of fitting parameters: $2\left(n_{i}, n_{j}\right)$

$$
q_{\mathrm{e}, j}=\frac{A_{i}\left(c_{\mathrm{e}, i} / \eta_{i}\right)}{1+\sum_{j=1}^{N} b_{j}\left(c_{\mathrm{e}, j} / \eta_{j}\right)^{\beta_{j}}}
$$

(h) Ideal adsorbed solution theory (IAST) with the mole fraction $z_{i}$, the spreading pressure $\varphi$, and the Freundlich parameters $K_{\mathrm{F}, i}$ and $n_{i}$ and the total loading $q_{\mathrm{T}}{ }^{29}$ number of fitting parameters: $2\left(\varphi, q_{\mathrm{T}}\right)$

$$
\begin{gathered}
\sum_{i=1}^{N} z_{i}=\sum_{i=1}^{N} \frac{c_{i}}{\left(\frac{\varphi n_{i}}{K_{\mathrm{F}, i}}\right)^{1 / n_{i}}}=1 \\
q_{\mathrm{T}}=\left[\sum_{i=1}^{N} \frac{z_{i}}{\varphi n_{i}}\right]^{-1}
\end{gathered}
$$

2.4.3. Parameter fitting and determination. All models described above use isotherm parameters derived from single- 
solute fittings. The parameter fitting was thus applied to the additional parameters for binary systems. The parameters were fitted by minimizing Marquardt's percent standard deviation (MPSD). ${ }^{36}$ The equation incorporates the degree of freedom into the geometric mean error distribution and was used by Srivastava et $a l^{31}$ for fitting of binary adsorption isotherms of cadmium and nickel onto bagasse fly ash. Through the incorporation of the degree of freedom a better comparison between models with different numbers of fitting parameters can be assured. $n_{\mathrm{m}}$ is the number of experimental data points and $n_{\mathrm{p}}$ the number of parameters in the isotherm equation.

$$
\operatorname{MPSD}=100 \sqrt{\frac{1}{n_{\mathrm{m}}-n_{\mathrm{p}}} \sum_{i=1}^{n}\left(\frac{q_{\mathrm{e}, i, \exp }-q_{\mathrm{e}, i, \mathrm{cal}}}{q_{\mathrm{e}, i, \exp }}\right)^{2}}
$$

To avoid finding results related to a local minimum of the minimization criteria a matrix of starting values containing at least 500 different combinations of the parameters was used. Thus, it was made sure to find the global minimum and the best fitting parameters.

\section{Results and discussion}

\subsection{Effect of $\mathbf{p H}$}

The single-solute adsorption isotherms for phosphate and silicate are dependent on the $\mathrm{pH}$ value and the water composition as shown in Fig. 1. Fitting parameters were obtained through linearization of the single-solute models and are listed in Table 1. The $\mu \mathrm{GFH}$ surface sites with a $\mathrm{pH}_{\mathrm{PZC}}$ of 7.5 react as acid or base dependent on the $\mathrm{pH} .{ }^{25}$ At $\mathrm{pH}$ values below the $\mathrm{pH}_{\mathrm{PZC}}$ the $\mu \mathrm{GFH}$ surface is positively charged and therefore the adsorption of anions is electrostatically favored. In the $\mathrm{pH}$ range of 6.0 to 8.0 phosphate is present as $\mathrm{HPO}_{4}{ }^{-}$and $\mathrm{H}_{2} \mathrm{PO}_{4}{ }^{2-}\left(\mathrm{p} K_{\mathrm{a}}=7.2\right)$ and thus adsorption capacity is higher for lower $\mathrm{pH}$ values. As the $\mathrm{pH}$ increases, more surface groups of the adsorbent are uncharged and negatively charged. Phosphate becomes twofold negatively charged. Thus the adsorption capacity decreases for $\mathrm{pH}$ values above the $\mathrm{pH}_{\mathrm{PZC}}$. Several studies revealed that phosphate forms strong inner-sphere complexes such as bidentate, binuclear or monodentate surface complexes with ferric (hydr)oxide. ${ }^{6,13,37}$

Silicate $\left(\mathrm{p} K_{\mathrm{a}}=9.8\right)$ loadings increase with increasing $\mathrm{pH}$, as shown in Fig. 1. Also, the percentage of polymeric (mostly dimeric) silicate rises with increasing $\mathrm{pH}$. Davis et al. ${ }^{38}$ suggested a direct sorption mechanism of monomeric and dimeric silicate to iron oxide surfaces, which leaves the surface with a net positive charge up to loadings of $1 \mathrm{~mol} \mathrm{~mol}^{-1}$ of adsorbent. The resulting negative surface charge acts electrostatically on the remaining free surface groups by increasing the fraction of protonated groups. ${ }^{13}$ This explains the high loadings of $28 \mathrm{mg}$ $\mathrm{g}^{-1}$ at initial concentrations of $10 \mathrm{mg} \mathrm{L}^{-1}$ silicate.

\subsection{Effect of water composition}

$\mathrm{P}$ loadings of approx. $17 \mathrm{mg} \mathrm{g}^{-1}$ were reached at an equilibrium concentration of $3 \mathrm{mg} \mathrm{L}^{-1} \mathrm{P}$ at $\mathrm{pH} 7.0$ with an ionic strength of
$10 \mathrm{mmol} \mathrm{L}^{-1}$. The adsorption in drinking water shows higher capacities with approx. $23 \mathrm{mg} \mathrm{g}^{-1} \mathrm{P}$. Several studies have shown that calcium, which occurs in concentrations up to $100 \mathrm{mg} \mathrm{L}^{-1}$ in Berlin drinking water, enhances the adsorption of phosphate $^{7,10}$ due to a suggested multi-layer coverage or the formation of ternary surface complexes. Furthermore, the possibility of surface precipitation of calcium phosphate was discussed. ${ }^{\mathbf{1 0 , 3 9}}$ Contrasting effects can be seen in the adsorption of silicate. In drinking water $\mu \mathrm{GFH}$ shows much lower silicate loadings than in DI water (17 $\mathrm{mg} \mathrm{g}^{-1}$ compared to $27 \mathrm{mg} \mathrm{g}^{-1}$ at $\left.c_{\mathrm{e}}=9 \mathrm{mg} \mathrm{L}^{-1}\right)$. The addition of $\mathrm{Ca}^{2+}$ to DI water with $\mathrm{NaCl}$ led to a rise in adsorption of approx. 15\%. The adsorption of calcium leads to a more positive surface charge of the adsorbent, resulting in higher adsorption capacities of silicate. Thus, the reduction in DW is linked to the presence of other competing anions. Bicarbonate was identified as main competitor for chromate adsorption onto $\mu \mathrm{GFH}^{40}$ and might also adversely impact silicate adsorption.

\subsection{Reversibility of adsorption}

The desorption isotherms of phosphate and silicate in DI + $\mathrm{NaCl}$ water are shown in Fig. 2, together with Freundlich isotherm fittings. In the case of phosphate (Fig. 2a), adsorption is partly reversible as indicated by partially overlapping ad-and desorption isotherms. An irreversible portion of adsorbed phosphate can also be observed, shown by the desorption isotherm being located above the adsorption isotherm around liquid-phase concentrations of $>0.1 \mathrm{mg} \mathrm{L}^{-1}$. Similar results with $16 \%$ of irreversible bonds and slow re-diffusion out of micropores were described by Cornell and Schwertmann. ${ }^{37}$ Atkinson et $a .^{41}$ explained the irreversibility by the formation of inert binuclear surface complexes. The adsorption isotherm of silicate is only partially shown in Fig. 2b. Independent of the loading reached during the adsorption phase, silicate desorbs down to an equilibrium concentration of approx. $2 \mathrm{mg} \mathrm{L}^{-1}$ in the desorption solution. Thus, high loadings remain in the adsorbent. High surface concentrations and contact times of silicate lead to the formation of oligomers and polymers and irreversible bonds to the hydroxide surfaces. This process is favoured by the neutral $\mathrm{pH}$ range. ${ }^{13}$ Padungthon and SenGupta $^{19}$ regenerated a silicate loaded fixed-bed adsorber and state that desorption of silicate is more difficult due to polymerization. The mole ratios applied in the present study ( $\mathrm{Si} / \mathrm{Fe}$ $=0.3$ to 0.6 ) exceeded by far the ratio above which polymerization occurs $(\mathrm{Si} / \mathrm{Fe}>0.1){ }^{20}$ Thus, the irreversible formation of $\mathrm{Si}-\mathrm{O}-\mathrm{Si}$ bonds is likely.

\subsection{Multi-component adsorption modelling}

Silicate competes with phosphate for adsorption sites and reduces P-loadings significantly (Fig. 3). Phosphate loadings are reduced by 27,33 and $47 \%\left(c_{\text {eq }}=1.5 \mathrm{mg} \mathrm{L}^{-1}\right)$ for 9,14 and $22 \mathrm{mg} \mathrm{\textrm {L } ^ { - 1 }} \mathrm{Si}$ respectively. The difference in loadings between the single-solute and the multi-component systems increases with decreasing adsorbent doses (and increasing residual Pconcentrations). Sorption competition is strongly influenced by kinetics and the sorption kinetics of phosphate are 

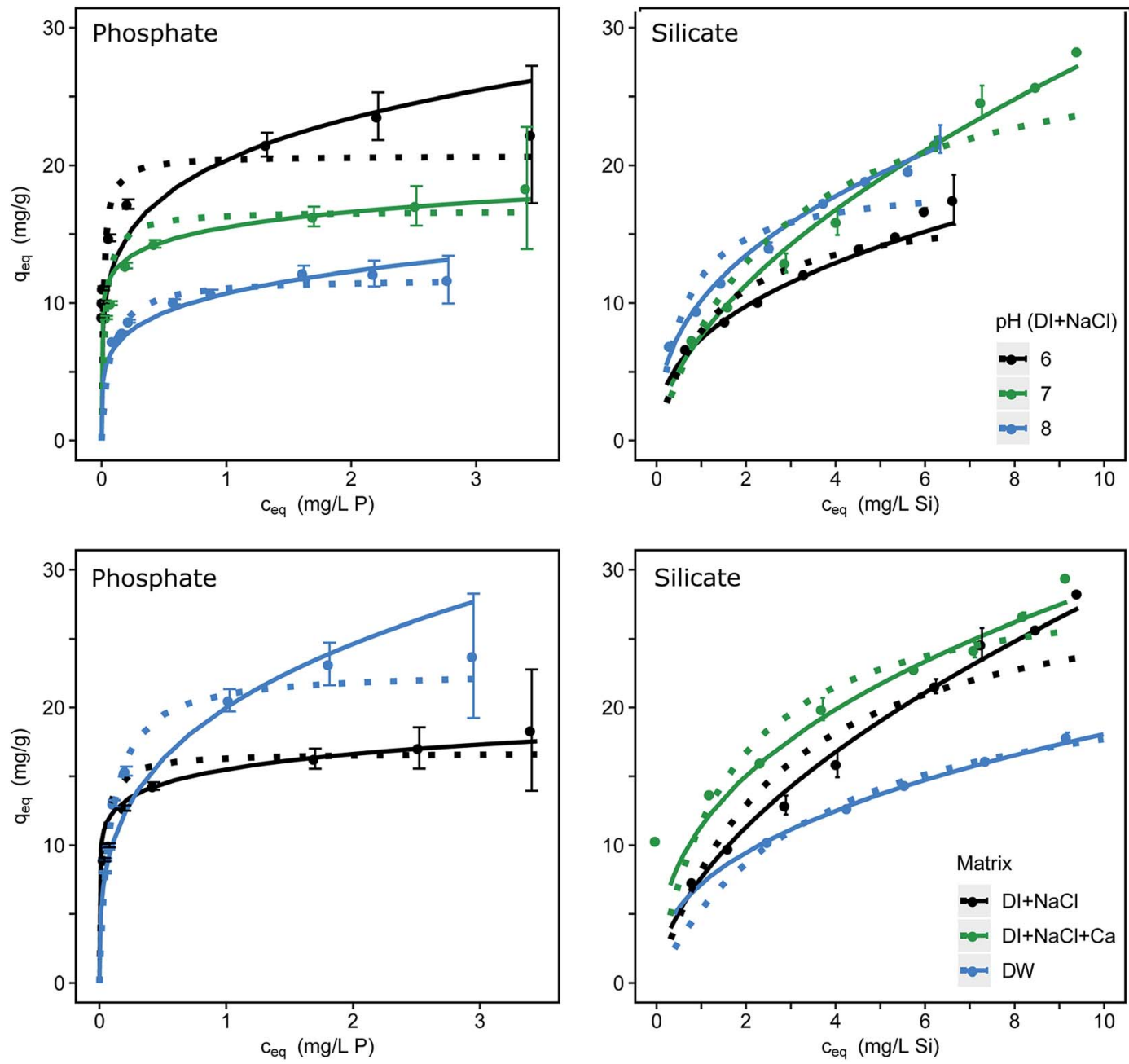

Fig. 1 Adsorption isotherms dependent on the $\mathrm{pH}$ (upper row) and on the water matrix (lower row) for phosphate and for silicate; errors indicate the $95 \%$ confidence interval; Freundlich isotherms as continuous and Langmuir as dotted lines fitted, with constants for pH 7.0 and DI provided in Table 1. Redlich-Peterson isotherm fittings are found in Fig. S1.†

considerably faster than the kinetics of silicate. ${ }^{40}$ The fraction of oligomeric silicates on the surface of the adsorbent steadily increases with time and loading. ${ }^{18}$ Especially at high loadings, silicate strongly competes with phosphate for limited adsorption sites. Silicate adsorption is also strongly affected by the presence of phosphate (Fig. 3). Through the addition of $5 \mathrm{mg} \mathrm{L}^{-1} \mathrm{P}$ the slope of the resulting isotherm changes from positive to negative and loadings are strongly reduced.

The adsorption data of silicate and phosphate in simultaneous adsorption was fitted using the different multi- component isotherm models (eqn (4)-(13)). Comparisons between experimentally obtained and calculated loadings are shown in the parity plots (Fig. 4). The closer the data points are to the bisecting line ( $45^{\circ}$ line), the better the respective model fits the experimental data. An exemplary application of the described models for the binary adsorption of phosphate and silicate with initial concentrations of 5 and $15 \mathrm{mg} \mathrm{L}^{-1}$ respectively is shown in Fig. $\mathrm{S} 2 \dagger$ as $2 \mathrm{D}$ isotherms. The associated MPSD values for all tested models are given in Table 2 and the isotherms are shown in Fig. S3 and S4. $\dagger$

Table 1 Isotherm parameters for the removal of phosphate and silicate by $\mu \mathrm{GFH}$ (pH 7.0, DI). A complete list can be found in Table S1

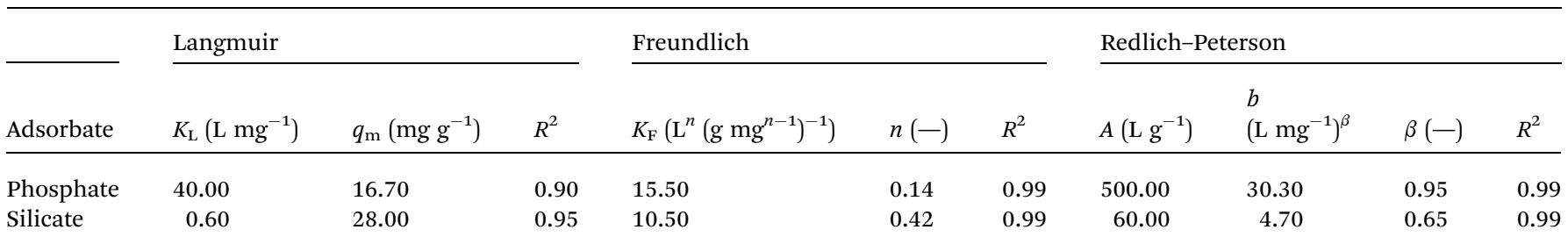



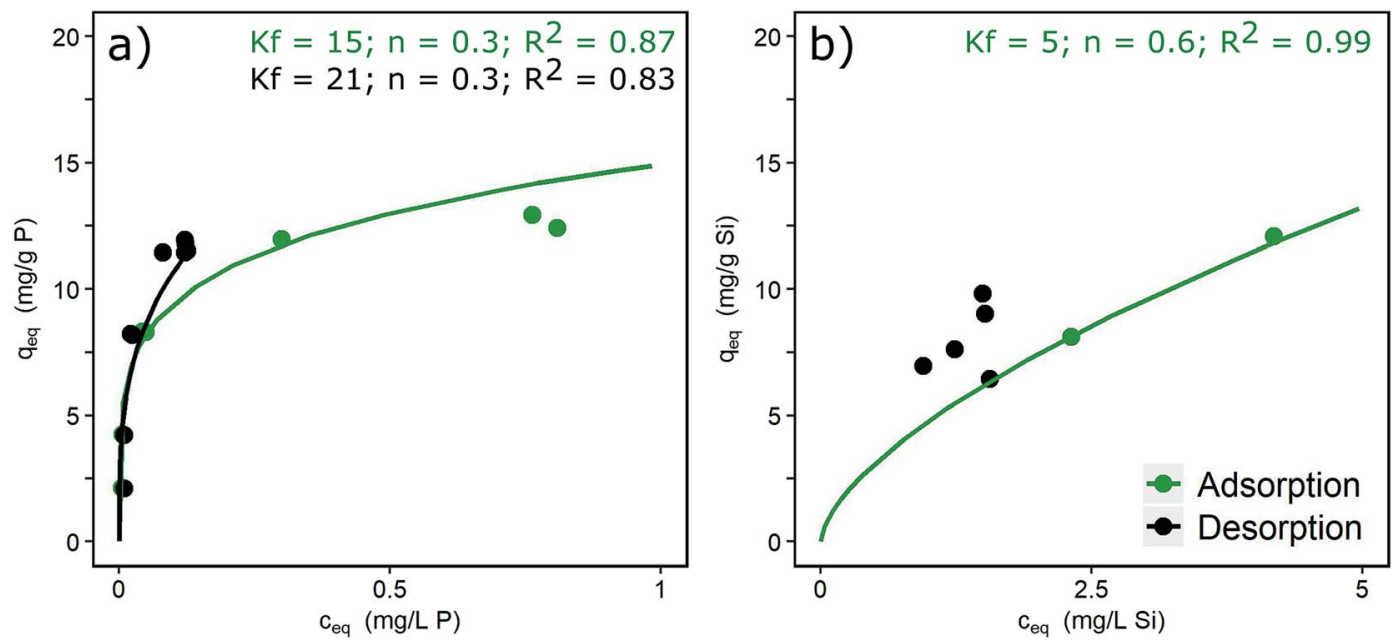

Fig. 2 Ad- and desorption isotherms for (a) phosphate $\left(c_{0}=3 \mathrm{mg} \mathrm{L}^{-1}\right)$ and (b) silicate $\left(c_{0}=10 \mathrm{mg} \mathrm{L}^{-1}\right)(\mathrm{pH} 7.0, \mathrm{DI}+\mathrm{NaCl})$ and Freundlich constants.

The non-modified Langmuir model (NMLM) creates a poor fit with a MPSD value of 80.6 as it presumes the adsorbates to adsorb independently without interaction. The introduction of the interaction term $\eta$ results in a better fit of the MLMI (MPSD $=61.0$ ) with a deviance of phosphate loadings below $30 \%$, but overestimated silicate loadings. Similar fittings were achieved using the extended Langmuir model (ELMI). The MLMI uses only two fitting parameters additionally to the singlecomponent Langmuir parameters whereas three parameters are used in the ELMI. As both models show similar fittings to the experimental data but the MLMI uses fewer fitting parameters it was chosen as the best Langmuir-type model.

However, the best fit with a MPSD value of 16.6 was obtained using the extended Freundlich equation assuming multilayer coverage (EFMI). This is expected as $\mu \mathrm{GFH}$ has heterogeneous surface sites and single solute isotherms were also well represented using the Freundlich model. Also, the EFMI used six fitting parameters additionally to the single-component Freundlich parameters. Thus, the interactive effects between phosphate and silicate are taken into account by the modification of the Freundlich equation. The resulting binary isotherms for phosphate and silicate are shown in Fig. 5. Phosphate loadings show a sharp increase for low phosphate or silicate concentrations, but only low additional adverse influences of silicate when its concentrations exceed $8 \mathrm{mg} \mathrm{L}^{-1}$. According to these results, even low silicate concentrations have strong negative effects on phosphate adsorption. Thus, an impact of silicate can be expected for most practical situations and water matrices. Silicate loadings are greatly reduced by the presence of phosphate, even at the lowest tested concentrations of $0.5 \mathrm{mg} \mathrm{L}^{-1}$. For P-concentrations of $1-5 \mathrm{mg} \mathrm{L}^{-1}$, the reduction of the loadings with silicate are almost constant.

The SRS model as another Freundlich derived model, but with only two fitting parameters shows a very good fit for silicate
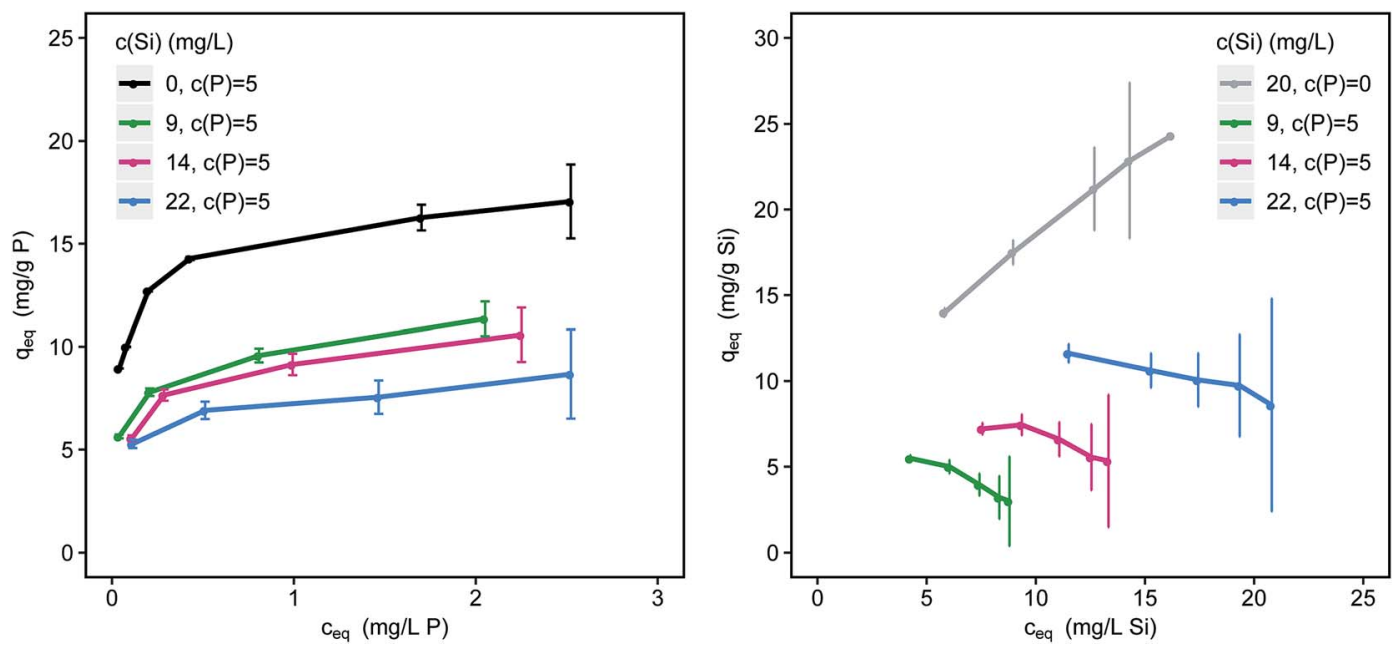

Fig. 3 Simultaneous adsorption of phosphate (left) and silicate (right) onto $\mu \mathrm{GFH}$ with increasing concentrations of silicate (pH 7.0, $\mathrm{DI}+\mathrm{NaCl}$ ); error bars indicate the $95 \%$ confidence interval. 

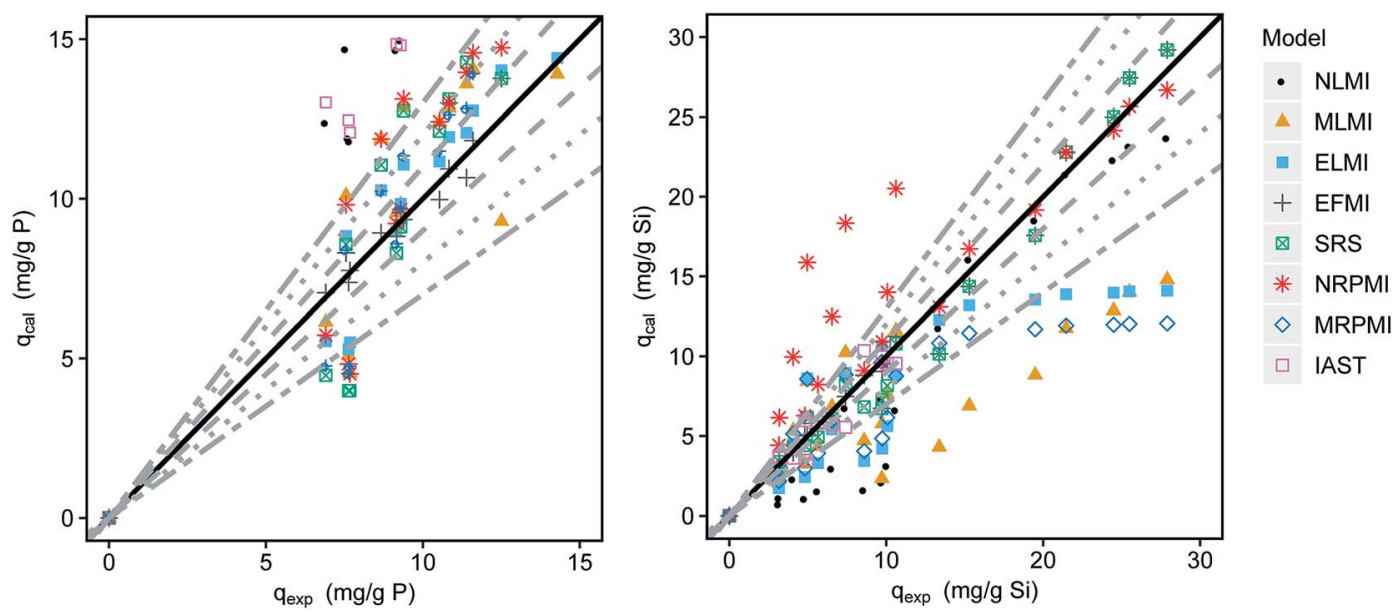

Fig. 4 Comparison of the experimental and calculated loadings of phosphate (left) and silicate (right) in the binary mixture of phosphate and silicate (dashed lines indicate 10\% deviation, dotted lines 20\% and alternately dashed lines 30\%).

Table 2 Multi-component isotherm parameters for the simultaneous adsorption of phosphate and silicate onto $\mu \mathrm{GFH}$

\begin{tabular}{|c|c|c|c|c|c|}
\hline \multirow{2}{*}{$\begin{array}{l}\text { Langmuir } \\
\text { Fitting parameter }\end{array}$} & \multirow{2}{*}{$\begin{array}{l}\begin{array}{l}\text { Non-modified } \\
\text { (NLMI) }\end{array} \\
-\end{array}$} & \multirow{2}{*}{\multicolumn{2}{|c|}{$\frac{\text { Modified (MLMI) }}{\eta_{i}}$}} & \multicolumn{2}{|c|}{$\begin{array}{l}\text { Extended } \\
\text { (ELMI) }\end{array}$} \\
\hline & & & & $K_{i}$ & $q_{\max }$ \\
\hline Phosphate & \multirow[b]{3}{*}{86.0} & \multicolumn{2}{|c|}{12.7} & 62.7 & 14.6 \\
\hline Silicate & & \multirow{2}{*}{\multicolumn{2}{|c|}{$\begin{array}{l}5.03 \\
61.0\end{array}$}} & 3.35 & 14.6 \\
\hline MPSD & & & & \multicolumn{2}{|l|}{53.3} \\
\hline Freundlich & \multicolumn{3}{|c|}{ Extended (EFMI) } & \multicolumn{2}{|c|}{$\begin{array}{l}\text { Sheindorf- } \\
\text { Rebuhn- } \\
\text { Sheintuch } \\
\text { (SRS) }\end{array}$} \\
\hline Fitting parameter & $x_{i}$ & $y_{i}$ & $z_{i}$ & $a_{1,2}$ & $a_{2,1}$ \\
\hline Phosphate & 0.11 & 0.15 & 0.78 & 0.09 & - \\
\hline Silicate & 0.78 & 27.3 & 0.41 & - & 713 \\
\hline MPSD & 16.6 & & & 38.4 & \\
\hline
\end{tabular}

\begin{tabular}{|c|c|c|}
\hline Redlich-Peterson & $\begin{array}{l}\text { Non-modified } \\
\text { (NRPMI) }\end{array}$ & Modified (MRPMI) \\
\hline Fitting parameter & - & $\eta_{i}$ \\
\hline Phosphate & & 0.57 \\
\hline Silicate & & 1.11 \\
\hline MPSD & 118 & 62.0 \\
\hline
\end{tabular}

Ideal adsorbed solution theory (IAST)

\begin{tabular}{llll}
\hline Fitting parameter & & $\phi$ & $q_{\mathrm{T}}$ \\
\hline MPSD & 55.1 & $92-200$ & $15.5-27.7$ \\
\hline
\end{tabular}

especially for higher loadings but an overestimation of up to $30 \%$ for phosphate loadings.

Both multi-component Redlich-Peterson isotherms do not reproduce the experimental values satisfactorily with errors exceeding $30 \%$ considerably. The modification with the interaction term decreases the MPSD value from 107 to 55.7.
The IAST as the only model based on thermodynamic considerations overestimates phosphate loadings by more than $30 \%$. The poor fit (MPSD of 55.1) is explained by the heterogeneity of adsorption sites of the iron hydroxide and the interaction of the adsorbates. Both phenomena are not considered in the model calculations.

Thus, the adsorption of phosphate in competition with silicate onto $\mu \mathrm{GFH}$ can be predicted using multi-component isotherms. Freundlich derived models were found to describe the system best with MPSD values of 38.4 and 16.6 for the SRS and the EFMI. The number of fitting parameters used has to be taken into consideration.

In systems with defined matrices, resulting loadings of both adsorbents can be calculated and predicted with the described models. For drinking water (loadings shown in Fig. 1) the found correlations are not sufficient, as a multitude of water constituents affect phosphate adsorption. Thus, for complex waters, like drinking water or waste water main competitors have to be identified and modelled in order to predict the removal of certain ions.

\subsection{Influence of contact time}

The contact time of silicate with the adsorbent prior to the addition of phosphate influences the loadings (Fig. 6). For $150 \mathrm{mg} \mathrm{L}^{-1} \mu \mathrm{GFH}$ P-loadings are reduced by 21 and $43 \%$ for 28 and $56 \mathrm{~d}$ compared to loadings at $7 \mathrm{~d}$. No significant influence $(<5 \%)$ was observed at high adsorbent doses of $600 \mathrm{mg} \mathrm{L}^{-1}$. At the same time, a significant increase (18\%) of silicate loadings in the single and binary system can be observed when increasing the contact time from 7 to $28 \mathrm{~d}$. No further increase was measured for $56 \mathrm{~d}$. This contradicts results from Christl et $a l^{18}$ who found a steady increase of silicate loadings on hematite over a time period of 210 days. Using ATR-FTIR spectroscopy, they measured a shift from monomeric to oligomeric and polymeric surface complexes over adsorption time. The competitive behaviour of chromate and silicate was studied by Zachara $e t$ al. ${ }^{42}$ Chromate adsorption was greatly reduced by the presence of silicate and the reduction increased with 

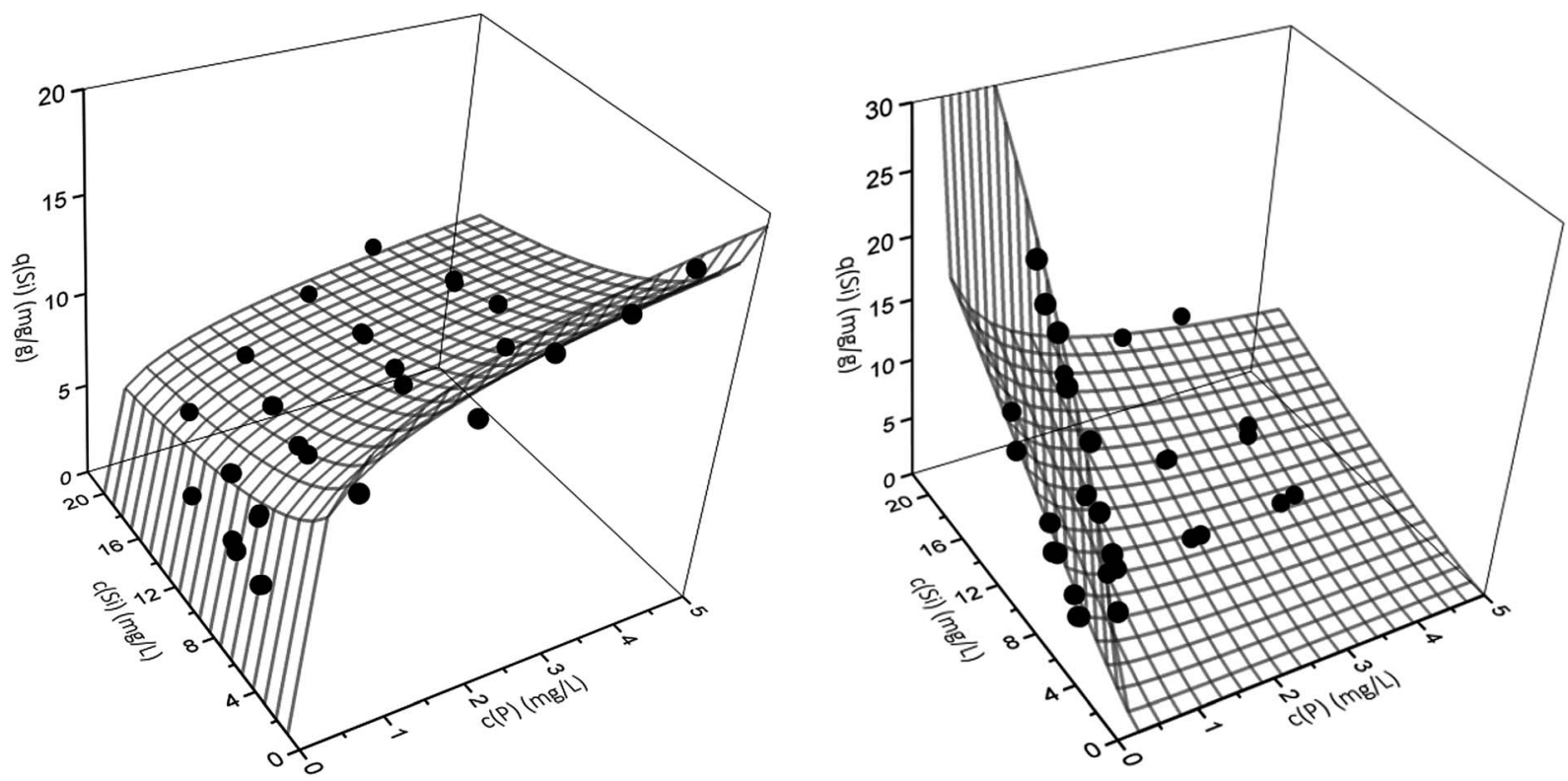

Fig. 5 Binary adsorption isotherms for the adsorption of phosphate (left) and silicate (right) onto $\mu$ GFH. Webs are predicted by the extended Freundlich model (EFMI) and symbols are experimental data.

increasing contact time (1-7 d) of silicate with an amorphous iron hydroxide. No further changes were observed between 7 and $28 \mathrm{~d}$ contact time. This effect was explained by silicate polymerization in solution and on the iron surface. Smith and Edwards ${ }^{43}$ described the reduction of arsenate adsorption onto amorphous iron hydroxide in the presence of silicate as highly time dependent. Silicate coats the accessible surface sites within minutes of contact, resulting in an anionic surface charge. As a monomeric surface layer has a thickness of approx. $0.1 \mathrm{~nm}$, physical blockage of the internal pores is unlikely at that stage. ${ }^{43}$ The negative surface charge however can hinder the diffusion of arsenate into the internal pores. With prolonged contact times of days and weeks, silicate forms polymers and an amorphous solid phase on the hydroxide surface with a thickness up to $100 \mathrm{~nm}$, thus blocking access to internal pores and preventing arsenate adsorption.

With $\mu \mathrm{GFH}$ as adsorbent and initial silicate concentrations of $10 \mathrm{mg} \mathrm{L}{ }^{-1}$, phosphate access to adsorption sites is not completely blocked, as can be inferred from only partially reduced phosphate loadings in Fig. 5. However, phosphate adsorption was reduced to $2.2 \mathrm{mg} \mathrm{g}^{-1}$ at low adsorbent doses and long contact times. As there is no difference in silicate adsorption between a contact time of 28 and $56 \mathrm{~d}$, but phosphate adsorption is further reduced, the formation of a coating layer preventing access to internal pores and hindering adsorption is likely.

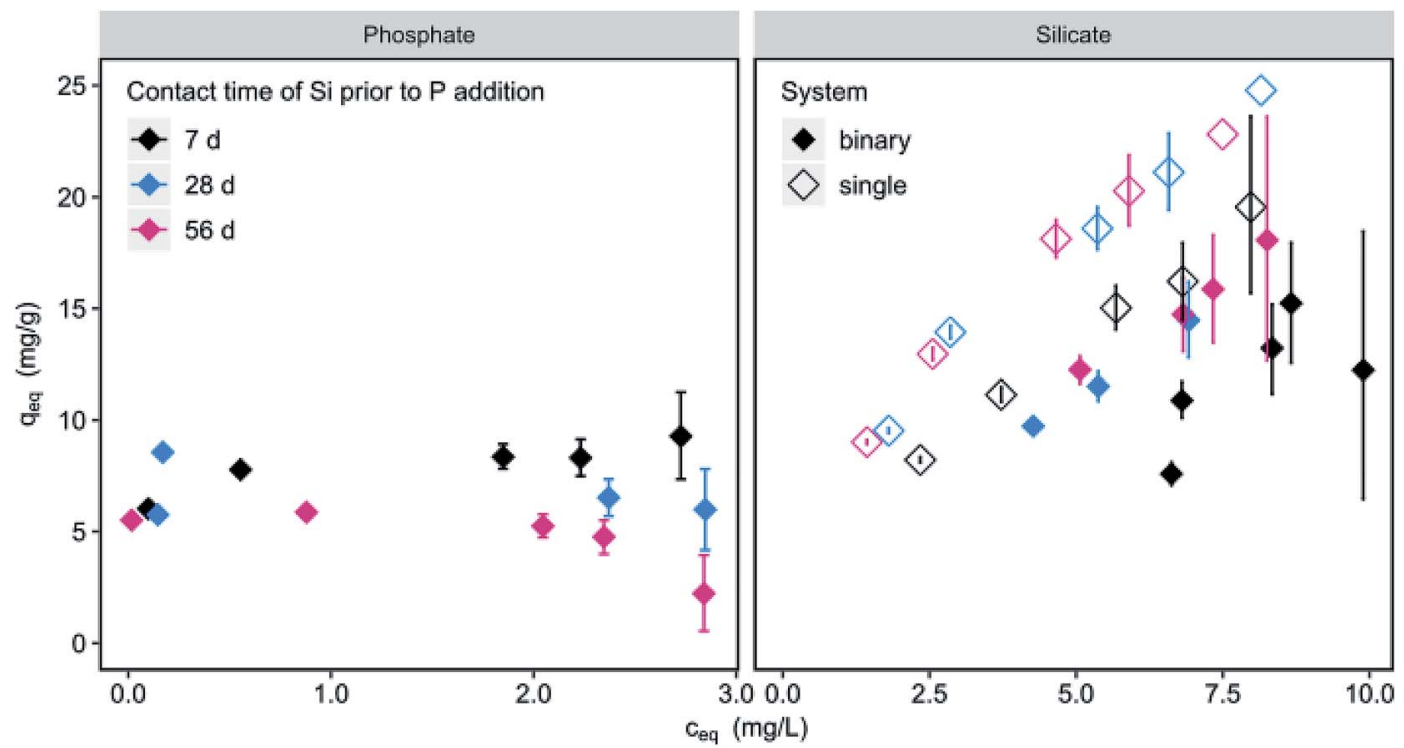

Fig. 6 Phosphate $\left(c_{0}=3 \mathrm{mg} \mathrm{L}^{-1}\right)$ and silicate $\left(c_{0}=10 \mathrm{mg} \mathrm{L}^{-1}\right)$ loadings as a function of silicate contact time of 7, 28 and 56 days prior to phosphate addition (filled diamonds) in contrast to silicate as single solute (blank diamonds) $\left(c(\mu \mathrm{GFH})=150 \mathrm{mg} \mathrm{L}{ }^{-1}, \mathrm{pH} 7.0, \mathrm{DI}+\mathrm{NaCl}\right.$ ). 
The order of addition does not lead to significantly differing loadings for phosphate or silicate at $\mathrm{pH}$ values of 7.0 and 8.0 at contact times of $7 \mathrm{~d}$ (Fig. S5 $\dagger$ ). At a pH of 6.0 however, the adsorbent surface is positively charged and thus favours anion adsorption. If phosphate $\left(c_{\mathrm{eq}}=2 \mathrm{mg} \mathrm{L}^{-1}\right)$ is added at a $\mathrm{pH}$ of 8.0 prior to silicate, resulting P-loadings are $26 \%$ higher than for later addition. Adsorption modelling using the double layer model (MINEQL5.0 with hydrous ferric hydroxide as adsorbent surface and $c(\mathrm{Fe})=76 \mathrm{mg} \mathrm{L}^{-1}, c(\mathrm{P})=2 \mathrm{mg} \mathrm{L}^{-1}, c(\mathrm{Si})=$ $10 \mathrm{mg} \mathrm{L}^{-1}$, ionic strength $=10 \mathrm{mmol} \mathrm{L}^{-1}$ ) predicts $\mathrm{Fe}-\mathrm{HPO}_{4}{ }^{-}$ (approx. 60\%) and $\mathrm{Fe}-\mathrm{PO}_{4}{ }^{2-}$ (approx. 35\%) as main resulting surface species (Fig. S6†). Only at $\mathrm{pH}$ values above $8.5 \mathrm{Fe}-\mathrm{PO}_{4}{ }^{2-}$ predominates. Silicate adsorbs exclusively as $\mathrm{Si}(\mathrm{OH})_{4}$ up to $\mathrm{pH}$ 8.0. When silicate adsorbs first, it shifts the $\mathrm{pH}_{\mathrm{PzC}}$ of iron hydroxides to lower values ${ }^{14}$ and thus impedes phosphate adsorption. Also, through the addition of silicate, previously adsorbed phosphate is replaced.

\section{Conclusions}

Competing effects of silicate strongly influence phosphate adsorption onto $\mu \mathrm{GFH}$. Phosphate loadings on $\mu \mathrm{GFH}$ were reduced by 14,23 and $41 \%$ in the presence of 6,10 and $18 \mathrm{mg} \mathrm{L}^{-1}$ silicate, respectively. If the number of adsorption sites is limited, phosphate outcompetes silicate while the influence of silicate rises with increasing numbers of available adsorption sites. Thus, monitoring of silicate concentrations and adjustments of adsorbent dose in phosphate elimination processes are necessary to ensure high P-removals. In contrast to phosphate, silicate bonds are mostly irreversible due to the proposed formation of $\mathrm{Si}-\mathrm{O}-\mathrm{Si}$ bonds on the surface of ferric hydroxides. Phosphate adsorption is favoured compared to silicate at lower $\mathrm{pH}$ values below the $\mathrm{pH}_{\mathrm{PZC}}$.

Binary isotherms could be fitted using the extended Freundlich equation assuming multi-layer coverage. Thus, resulting loadings of both adsorbates in competition can be predicted using the fitted model parameters. The models provide means to control phosphate elimination in water works applications. Real water samples contain a multicity of water constituents and additional effects are expected. However, the gained knowledge helps to understand the processes taking place in real water matrices.

Phosphate adsorption highly depends on the contact time of the iron hydroxide surface in silicate solution. An increase in contact time prior to phosphate addition from 7 to 28 and 56 d led to a decrease of 21 and $43 \%$ in P-loadings, respectively. Simultaneously, only minor silicate replacement by phosphate was observed, further underlining partially irreversible silicate adsorption. Thus, the formation of a coating layer resulting from silicate polymerization is likely to hinder access to adsorption sites reducing successful phosphate removal in applications with high silicate concentrations.

\section{Conflicts of interest}

The authors declare no conflict of interest.

\section{Acknowledgements}

The current investigations as part of the German-Israeli project AdsFilt (02WIL1389) are funded by the German Ministry of Education and Research (BMBF) within the framework of the German-Israeli Water Technology Cooperation. We acknowledge support by the German Research Foundation and the Open Access Publication Fund of TU Berlin.

\section{References}

1 European waters. Assessment of status and pressures 2018, Publications Office of the European Union, Luxembourg, 2018.

2 Regulation for the protection of surface waters, OGewV, 2016.

3 A. M. Dolman, U. Mischke and C. Wiedner, Lake-typespecific seasonal patterns of nutrient limitation in German lakes, with target nitrogen and phosphorus concentrations for good ecological status, Freshwater Biol., 2016, 61, 444456, DOI: $10.1111 /$ fwb.12718.

4 M. Li, J. Liu, Y. Xu and G. Qian, Phosphate adsorption on metal oxides and metal hydroxides: a comparative review, Environ. Rev., 2016, 24, 319-332, DOI: 10.1139/er-2015-0080.

5 S. Mustafa, G. Nawab, A. Naeem, N. Rehana and B. Dilara, Temperature effect on phosphate sorption by iron hydroxide, Environ. Technol., 2004, 25, 1-6, DOI: 10.1080/ 09593330409355432b.

6 R. P. J. J. Rietra, T. Hiemstra and W. H. van Riemsdijk, Interaction between Calcium and Phosphate Adsorption on Goethite, Environ. Sci. Technol., 2001, 35, 3369-3374, DOI: 10.1021/es000210b.

7 A. Sperlich, PhD Dissertation, Technische Universität, Berlin, 2010.

8 G. Zelmanov and R. Semiat, The influence of competitive inorganic ions on phosphate removal from water by adsorption on iron $(\mathrm{Fe}+3)$ oxide/hydroxide nanoparticlesbased agglomerates, J. Water Process Eng., 2015, 5, 143-152, DOI: 10.1016/j.jwpe.2014.06.008.

9 T. Hiemstra, M. O. Barnett and W. H. van Riemsdijk, Interaction of silicic acid with goethite, $\mathrm{J}$. Colloid Interface Sci., 2007, 310, 8-17, DOI: 10.1016/j.jcis.2007.01.065.

$10 \mathrm{Y}$. Gao and A. Mucci, Individual and competitive adsorption of phosphate and arsenate on goethite in artificial seawater, Chem. Geol., 2003, 199, 91-109, DOI: 10.1016/S0009-2541(03) 00119-0.

11 L. Sigg and W. Stumm, The interaction of anions and weak acids with the hydrous goethite $(\alpha$-FeOOH $)$ surface, Colloids Surf., 1981, 2, 101-117.

12 J. S. Geelhoed, T. Hiemstra and W. H. van Riemsdijk, Phosphate and sulfate adsorption on goethite: single anion and competitive adsorption, Geochim. Cosmochim. Acta, 1997, 61, 2389-2396, DOI: 10.1016/S0016-7037(97)00096-3.

13 T. Hiemstra, Ferrihydrite interaction with silicate and competing oxyanions: geometry and hydrogen bonding of surface species, Geochim. Cosmochim. Acta, 2018, 238, 453476, DOI: 10.1016/j.gca.2018.07.017. 
14 T. P. Luxton, C. J. Tadanier and M. J. Eick, Mobilization of Arsenite by Competitive Interaction with Silicic Acid, Soil Sci. Soc. Am. J., 2006, 70, 204, DOI: 10.2136/sssaj2005.0101.

15 T. P. Luxton, Master thesis, Faculty of the Virginia Polytechnic Institute and State University, 2002.

16 P. J. Swedlund, R. D. Hamid and G. M. Miskelly, Insights into $\mathrm{H}(4) \mathrm{SiO}(4)$ surface chemistry on ferrihydrite suspensions from ATR-IR, Diffuse Layer Modeling and the adsorption enhancing effects of carbonate, J. Colloid Interface Sci., 2010, 352, 149-157, DOI: 10.1016/j.jcis.2010.08.011.

17 P. J. Swedlund, S. Sivaloganathan, G. M. Miskelly and G. I. N. Waterhouse, Assessing the role of silicate polymerization on metal oxyhydroxide surfaces using X-ray photoelectron spectroscopy, Chem. Geol., 2011, 285, 62-69, DOI: 10.1016/j.chemgeo.2011.02.022.

18 I. Christl, Y. Brechbühl, M. Graf and R. Kretzschmar, Polymerization of silicate on hematite surfaces and its influence on arsenic sorption, Environ. Sci. Technol., 2012, 46, 13235-13243, DOI: 10.1021/es303297m.

19 S. Padungthon and A. SenGupta, Comment on "Polymerization of silicate on hematite surfaces and its influence on arsenic sorption", Environ. Sci. Technol., 2013, 47, 5514-5515, DOI: 10.1021/es4014689.

20 P. Swedlund, Adsorption and polymerisation of silicic acid on ferrihydrite, and its effect on arsenic adsorption, Water Res., 1999, 33, 3413-3422, DOI: 10.1016/S0043-1354(99) 00055-X.

21 I. Hilbrandt, A. S. Ruhl and M. Jekel, Conditioning Fixed-Bed Filters with Fine Fractions of Granulated Iron Hydroxide (GFH), Water, 2018, 10(10), 1324, DOI: 10.3390/w10101324.

22 W. Driehaus, M. Jekel and U. Hildebrandt, Granular ferric hydroxide - a new adsorbent for the removal of arsenic from natural water, Aqua, 1998, 47, 30-35.

23 Y. Matsui, N. Ando, T. Yoshida, R. Kurotobi, T. Matsushita and K. Ohno, Modeling high adsorption capacity and kinetics of organic macromolecules on super-powdered activated carbon, Water Res., 2011, 45, 1720-1728, DOI: 10.1016/j.watres.2010.11.020.

24 C. Bahr, PhD Dissertation, Technische Universität, Berlin, 2012.

25 B. Saha, R. Bains and F. Greenwood, Physicochemical characterization of granular ferric hydroxide (GFH) for arsenic(V) sorption from water, Sep. Sci. Technol., 2005, 40, 2909-2932, DOI: 10.1080/01496390500333202.

26 I. Hilbrandt, H. Shemer, A. S. Ruhl, R. Semiat and M. Jekel, Comparing fine particulate iron hydroxide adsorbents for the removal of phosphate in a hybrid adsorption/ ultrafiltration system, Sep. Purif. Technol., 2019, 221, 23-28, DOI: 10.1016/j.seppur.2019.03.044.

27 G. Aschermann, F. Zietzschmann and M. Jekel, Influence of dissolved organic matter and activated carbon pore characteristics on organic micropollutant desorption, Water Res., 2018, 133, 123-131, DOI: 10.1016/ j.watres.2018.01.015.

28 ISO, Water quality - determination of orthophosphate and total phosphorus contents by flow analysis (FIA and CFA). Part 1: method by flow injection analysis (FIA), 2003.
29 E. Worch, Adsorption Technology in Water Treatment Fundamentals, Processes and Modeling, De Gruyter $\mathrm{GmbH}$, Berlin/Boston, 2012.

30 S. K. Papageorgiou, F. K. Katsaros, E. P. Kouvelos and N. K. Kanellopoulos, Prediction of binary adsorption isotherms of $\mathrm{Cu}(2+), \mathrm{Cd}(2+)$ and $\mathrm{Pb}(2+)$ on calcium alginate beads from single adsorption data, J. Hazard. Mater., 2009, 162, 1347-1354, DOI: 10.1016/ j.jhazmat.2008.06.022.

31 V. C. Srivastava, I. D. Mall and I. M. Mishra, Equilibrium modelling of single and binary adsorption of cadmium and nickel onto bagasse fly ash, Chem. Eng. J., 2006, 117, 79-91, DOI: 10.1016/j.cej.2005.11.021.

32 R. T. Yang, Gas Separation by Adsorption Processes, Elsevier Science, Burlington, 1987.

33 E. Padilla-Ortega, R. Leyva-Ramos and J. V. Flores-Cano, Binary adsorption of heavy metals from aqueous solution onto natural clays, Chem. Eng. J., 2013, 225, 535-546, DOI: 10.1016/j.cej.2013.04.011.

34 C. Sheindorf, M. Rebhun and M. Sheintuch, A Freundlichtype multicomponent isotherm, J. Colloid Interface Sci., 1981, 79, 136-142, DOI: 10.1016/0021-9797(81)90056-4.

35 V. C. Srivastava, I. D. Mall and I. M. Mishra, Removal of cadmium(II) and zinc(II) metal ions from binary aqueous solution by rice husk ash, Colloids Surf., A, 2008, 312, 172184, DOI: 10.1016/j.colsurfa.2007.06.048.

36 D. W. Marquardt, An Algorithm for Least-Squares Estimation of Nonlinear Parameters, J. Soc. Ind. Appl. Math., 1963, 11, 431-441, DOI: 10.1137/0111030.

37 R. M. Cornell and U. Schwertmann, The iron oxides: structure, properties, reactions, occurrences and uses, Wiley-VCH, Weinheim, 2nd edn, 2003.

38 C. C. Davis, H.-W. Chen and M. Edwards, Modeling Silica Sorption to Iron Hydroxide, Environ. Sci. Technol., 2002, 36, 582-587, DOI: 10.1021/es010996t.

39 L. Li and R. Stanforth, Distinguishing Adsorption and Surface Precipitation of Phosphate on Goethite (alphaFeOOH), J. Colloid Interface Sci., 2000, 230, 12-21, DOI: 10.1006/jcis.2000.7072.

40 I. Hilbrandt, A. S. Ruhl, F. Zietzschmann, M. Molkenthin and $\mathrm{M}$. Jekel, Competition in chromate adsorption onto micro-sized granular ferric hydroxide, Chemosphere, 2019, 218, 749-757, DOI: 10.1016/j.chemosphere.2018.11.152.

41 R. J. Atkinson, A. M. Posner and J. P. Quirk, Kinetics of isotopic exchange of phosphate at the $\alpha$-FeOOH-aqueous solution interface, J. Inorg. Nucl. Chem., 1972, 34, 22012211, DOI: 10.1016/0022-1902(72)80152-0.

42 J. M. Zachara, D. C. Girvin, R. L. Schmidt and C. T. Resch, Chromate adsorption on amorphous iron oxyhydroxide in the presence of major groundwater ions, Environ. Sci. Technol., 1987, 21, 589-594, DOI: 10.1021/es00160a010.

43 S. D. Smith and M. Edwards, The influence of silica and calcium on arsenate sorption to oxide surfaces, Aqua, 2005, 54, 201-211, DOI: 10.2166/aqua.2005.0019. 